\title{
Análise interactômica da VDAC (voltage-dependent anion selective channel) nos cérebros aviar, bovino e murino ${ }^{1}$
}

\author{
Carla Rossini Crepaldi² ${ }^{2}$ Flávia Simone Munin², Phelipe Augusto Mariano Vitale ${ }^{2}$ \\ e Marcelo de Cerqueira César ${ }^{2 *}$
}

\begin{abstract}
Crepaldi C.R., Munin F.S., Vitale P.A.M. \& Cerqueira César M. 2011. [Interactomic analysis of VDAC (voltage-dependent anion selective channel) in rat, bovine and chicken brain.] Análise interactômica da VDAC (voltage dependent anion selective channel) nos cérebros aviar, bovino e murino. Pesquisa Veterinária Brasileira 31(11):10311038. Laboratório de Neurociência e Proteômica, Faculdade de Zootecnia e Engenharia de Alimentos, Universidade de São Paulo, Av. Duque de Caxias Norte 225, Pirassununga, SP 13635-900, Brazil. E-mail: mccesar@usp.br

The voltage dependent anion channel (VDAC) is the most abundant protein of outer mitochondrial membrane. VDAC controls metabolite exchange through this membrane and the apoptosis machinery. Interactomics is the study of protein complexes, their interactions and the consequences of these interactions. In our case we studied the interactome of the hexokinase-VDAC-ANT (adenine nucleotide transporter) complex in mitochondria of neuronal cells from rat, bovine and chicken brain. We wished to understand if the differential expression of VDAC1 and VDAC2 verified in these cells was linked to differences in the interactions between proteins in these complexes. Our results showed that avian and bovine neurons had more protein complexes (5) containing VDAC than rat cells (1), which indicates a differential kinetics of assembly or disassembly. Moreover, mitochondrial neuronal chicken VDAC interacts with more proteins in comparison with bovine neuronal VDAC, which is indicative of a differential subunit composition. These results supported evidences of differential apoptotic and energetic mechanisms between these brains.
\end{abstract}

INDEX TERMS: VDAC, Hexokinase, interactome, epilepsy, mitochondria, neuron, brain.

RESUMO.- A VDAC é a proteína mais abundante na membrana mitocondrial externa. Exerce o controle da atividade desta organela através da regulação da troca de metabólitos e tem função crucial no mecanismo de apoptose. Em nosso caso, os estudos dos complexos protéicos, das interações entre a VDAC e outras proteínas presentes no interior do neurônio que auxiliam na manutenção das funções das organelas e da célula, fazem parte da chamada interactômica. 0 presente estudo determinou o interactoma do complexo protéico Hexoquinase-VDAC-ANT presente em cérebros murino, bovino e aviar. Nosso objetivo foi identificar se as expressões diferenciadas da VDAC1 e VDAC2 verificadas nos cérebros murino, aviar e bovino, estão associadas a diferenças nos interac-

\footnotetext{
${ }^{1}$ Recebido em 6 de abril de 2011.

Aceito para publicação em 2 de agosto de 2011.

${ }^{2}$ Departamento de Ciências Básicas, Faculdade de Zootecnia e Engenharia de Alimentos, Universidade de São Paulo (USP), Av. Duque de Caxias Norte 225, Pirassununga, SP 13630-000, Brazil. *Autor para correspondência: mccesar@usp.br
}

tomas dessas proteínas. Este estudo revelou que as espécies aviar e bovina apresentaram o maior número de complexos protéicos contendo VDACs (5) quando comparadas com os neurônios de rato (1), o que é indicativo de uma cinética diferencial de montagem ou desmontagem do complexo. Além disso, a VDAC mitocondrial neuronal aviar também interage com mais proteínas em relação à VDAC mitocondrial neuronal bovina, o que é resultado de uma composição de subunidades diferenciada. Tais resultados indicam diferenças significativas quanto ao metabolismo energético e apoptótico no cérebro aviar, bovino e murino, existindo interações diferenciais da VDAC no cérebro aviar.

TERMOS DE INDEXAÇÃO: VDAC, Hexoquinase, interactôma, epilepsia, mitocôndria, neurônio, cérebro.

\section{INTRODUÇÃo}

A VDAC (voltage dependent anion selective channel) é a proteína mais abundante na membrana mitocondrial externa (Desagher \& Martinou 2000), que se notabililiza por estar 
associada primeiramente à regulação de trocas metabólicas entre a mitocôndria e o citosol e em segundo pela morte celular apoptótica, e por fim ao desenvolvimento de doenças neurodegenerativas (Törnroth-Horsefield \& Neutze 2008).

A VDAC compõe também o poro de transição de permeabilidade da membrana (PTP), o qual também é constituído pelo ANT (adenine nucleotide transporter) na membrana mitocondrial interna e pela ciclofilina D na matriz mitocondrial. O PTP realiza o contato entre a membrana externa e a membrana interna da mitocôndria. A abertura desse canal ocorre quase que universalmente durante a apoptose, o que tem repercussões letais como a interrupção da fosforilação oxidativa e a liberação mitocondrial de proteínas apoptóticas necessárias à ativação da cascata de caspases e endonucleases (Rodriguez-Enriquez et al. 2004).

A VDAC possui 3 isoformas: VDAC 1, VDAC 2 e VDAC 3 presentes em mamíferos (Rahmani et al.1998). A super-expressão da VDAC 1 em uma variedade de células promove a morte celular apoptótica através da formação do complexo pró-apoptótico VDAC 1-Bax, o qual induz uma mudança no potencial da membrana e liberação do citocromo c (Kroemer et al. 2007). Células com baixa expressão da VDAC 1 proliferam lentamente, devido à troca limitada de ATP/ADP entre o citosol e a mitocôndria, indicando que a VDAC 1 é necessária para o crescimento normal da célula (Abu-Hamad et al. 2006). Cheng et al. (2003) demonstraram que a super-expressão da VDAC 2 previne a ativação da BAK e inibe a via apoptótica mitocondrial. A VDAC 2 é capaz de interagir especificamente com a conformação inativa de BAK. Dessa forma, observa-se em literaturas que a VDAC 1 possui propriedades pró-apoptóticas, enquanto que a VDAC 2 propriedades anti-apoptóticas.

Nesse sentido o desarranjo das VDACs pode mediar processos apoptóticos, mitocondriais e disfunções sinápticas, que estão associadas a desordens neurodegenerativas (Törnroth-Horsefield \& Neutze 2008). Relacionando o desarranjo das VDACs a desordens degenerativas observou-se em pacientes com Mal de Alzheimer uma diminuição dos níveis totais de VDAC1 no córtex frontal e no tálamo. Esses resultados parecem estar associados à perda sináptica e neuronal, comum em pacientes com Mal de Alzheimer (Yoo et al. 2001). A VDAC também altera-se no Mal de Parkinson (Hastings 2009).

A epilepsia é a desordem neurológica mais comum em humanos, a qual acomete aproximadamente $1 \%$ da população mundial. A morte súbita em epilepsia é a causa mais comum de óbito relacionado diretamente à epilepsia. As causas patofisiológicas exatas da morte súbita são desconhecidas, mas é provável que as anormalidades cardíacas durante e entre as crises têm relação importante com a mesma. Similarmente, a síndrome da morte súbita em aves é uma doença caracterizada por uma morte aguda em aves bem-nutridas e aparentemente saudáveis. A incidência da síndrome da morte súbita em aves varia entre 0,5 a $5 \%$ o qual representa a principal perda econômica da indústria avícola. Além disso, foi proposto que um controle desbalanceado da atividade cardíaca pelo sistema nervoso central esteja relacionado a uma possível causa de arritmia letal de morte súbita em Gallus gallus (Scorza et al. 2009).
Devido às similaridades entre a morte súbita em epilepsia e morte súbita em aves e como a manifestação comportamental em Gallus gallus durante o fenômeno de morte súbita é bastante similar a crises tônico-clônicas, estudos sugerem que a epilepsia pode ser um novo fator possível para a síndrome da morte súbita. Devido a essa similaridade clínica, o modelo experimental de epilepsia em frangos tem sido utilizado como método de estudos de epilepsia em humanos (Scorza et al. 2009).

Neste sentido, Jiang et al. (2007) reportaram a correlação da epilepsia com alterações na função mitocondrial neuronal. Valores aumentados no nível de VDAC 1 e diminuídos de VDAC 2 foram observados em grupos de pacientes fármaco-resistentes à epilepsia, o que pode estar relacionado com a diminuição da produção e translocação de ATP mitocondrial. Esta diminuição causa falha energética e agrava a disfunção mitocondrial. Perfil de expressão semelhante das VDACs 1 e 2 foi encontrado em nosso laboratório em neurônios corticais de cérebro aviar (Poleti et al. 2010), quadro semelhante ao da epilepsia fármaco-resistente de humanos.

A VDAC também realiza interações com moléculas que necessitam ter acesso preferencial ao ATP no neurônio, uma delas é a hexoquinase. Existem dois tipos de ligação da hexoquinase a mitocôndria, denominados de sítio A e sítio $B$, conforme ilustrado na Figura 1. A proporção dos sítios tipo A e B varia em função da espécie animal a partir da qual as mitocôndrias neuronais são extraídas. Essa proporção é de 90:10, 40:60 e 20:80 nos cérebros de rato, bovino e humano, respectivamente (Cerqueira César \& Wilson 2002, Cerqueira César \& Wilson 2004).

0 presente trabalho trouxe como contribuição a descrição dos complexos protéicos que possuem as VDACs associadas, através da determinação do número de proteínas envolvidas, e a quantificação dos pesos moleculares dos componentes dos diferentes complexos dos quais as VDACs fazem parte. Nosso objetivo foi inquirir se as expressões diferenciadas da VDAC1 e VDAC2 verificadas nos cérebros murino, aviar e bovino, observadas em estudo anterior

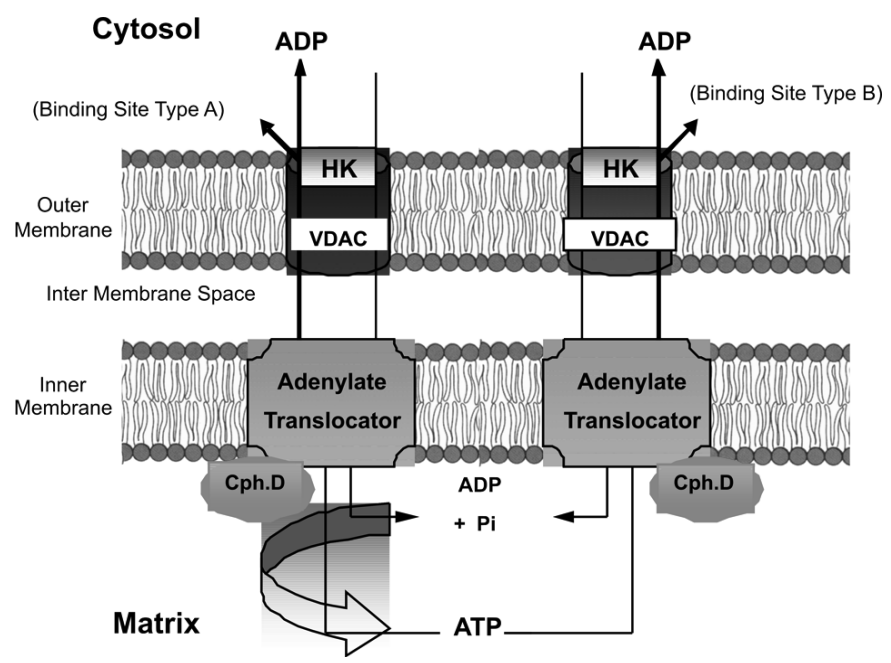

Fig.1. Esquema de acoplamento da Hexoquinase a VDAC. Um sistema que utiliza e produz ATP em cérebros. Observe os dois tipos de sítios de ligação da hexoquinase à VDAC. 
(Poleti et al., 2010), estão associadas a diferenças nos interactomas dessas proteínas nesses tecidos.

\section{MATERIAL E MÉTODOS}

Diversas técnicas podem ser utilizadas para estudar as interações entre as proteínas. A técnica eleita para isolar as diferentes proteínas envolvidas no complexo protéico foi a eletroforese em condições nativas (BN-PAGE) a qual separa proteínas em uma faixa de massa de $10 \mathrm{KDa}$ a $10 \mathrm{MDa}$ (Wittig et al. 2010, Swamy et al. 2006).

0 princípio de separação do BN/SDS PAGE consiste na primeira dimensão, em uma separação de complexos protéicos solubilizados em estado nativo. Já na segunda dimensão, ocorre uma separação das subunidades do complexo. Em ambas as dimensões, a separação ocorre primariamente pelo peso molecular (Reisinger \& Eichacker 2007).

O BN-PAGE fornece-nos a tecnologia necessária para uma separação em alta resolução dos complexos protéicos de membrana, permitindo a análise estequiométrica de uma subunidade específica de um complexo protéico, tão bem como de um conjunto de complexos protéicos.

No presente estudo, os córtices cerebrais de bovinos foram retirados e pesados logo após o abate dos animais no matadouro escola da USP, Campus de Pirassununga. Para cada extrato foram utilizadas $5 \mathrm{~g}$ de córtex. Para aves e ratos, os cérebros íntegros foram retirados da caixa cranial e utilizadas também $5 \mathrm{~g}$ de tecido, o que equivale a 3 cérebros. Esses cérebros foram utilizados ainda frescos ou imediatamente congelados em nitrogênio líquido para uso posterior.

Isolamento mitocondrial. 0 isolamento mitocondrial de tecido cerebral foi realizado segundo o artigo proposto por Lai \& Clark (1979). 0 cérebro foi finamente picotado em meio de isolamento contendo Sacarose 0,25M (código S-9378, Sigma), EGTA 0,1mM (código1093 053, Boehringer Mannheim GmbH), MOPS $5 \mathrm{mM}$ (código M1254, Sigma) pH 7,4 e 1\% de Inibidores de Protease (Amersham Biosciences) refrigerado a $4^{\circ} \mathrm{C}$. A homogeneização foi realizada em homogeneizador tipo Potter,e em seguida, o homogenato foi centrifugado a $1940 \mathrm{~g}$ durante 3 minutos. 0 sobrenadante foi retirado, transferido para outro tubo e centrifugado a $16000 \mathrm{~g}$ por $8 \mathrm{~min}$. 0 sobrenadante foi descartado e o pellet re-suspenso em meio de Ficoll 3\% e distribuído no topo de um tubo contendo 25mL de meio de Ficoll 6\% contendo Manitol 0,24 M (código M9647, Sigma), EGTA 0,1mM, Sacarose $60 \mathrm{mM}$, MOPS 5mM, 6\% Ficoll PM400 (código 17-0300-10, GE Healthcare) e $1 \%$ de inibidores de protease e centrifugado a $14600 \mathrm{~g}$ por $30 \mathrm{~min}$. Em seguida, o sobrenadante foi descartado e o pellet re-suspenso em meio de isolamento e centrifugado a $15100 \mathrm{~g}$ por 10 minutos. Após a centrifugação o pellet resultante foi gentilmente re-suspenso em $0,4 \mathrm{~mL}$ de meio de isolamento. As proteínas totais foram determinadas através do kit BCA Protein Assay Kit (código 23225, Pierce) utilizando como padrão uma solução de albumina bovina. As mitocôndrias isoladas foram armazenadas em nitrogênio líquido.

Solubilização das proteínas de membrana mitocondriais. Para a solubilização das proteínas mitocondriais foi utilizado o detergente Dodecylmaltoside (DDM) (código d4641, Sigma) a $1 \%$, segundo proposto por Reisinger \& Eichacker (2007), que recomendam uma concentração entre $0,055 \%$ e 7\%, diluído em tampão de Lise contendo Bis-Tris 50mM (código 12112, USB Corporation), ácido 6-aminohexanóico 500mM (código A2504, Sigma) $\mathrm{pH} 7,0$. Foi adicionado Mix de inibidores de protease (código 80-6501-23, Amersham Biosciences) numa proporção de 1:100 (v:v) e as amostras foram incubadas por 1 hora em gelo, e re-suspensas a cada $15 \mathrm{~min}$. As amostras foram centrifugadas a 15000 rpm a $4^{\circ} \mathrm{C}$ durante 1 hora. Após a centrifugação foi medido o vo- lume de cada amostra e então adicionado o tampão da amostra (ácido 6-aminohexanóico 500 mM, 8\% de Comassie Blue G250, numa proporção de 4 DDM:1 Comassie (v:v) e mix de inibidores de protease 1:100).

Eletroforese BN/PAGE. A eletroforese em condições nativas foi realizada segundo técnica descrita por Schägger et al. (1994) com algumas modificações. O BN-PAGE foi executado utilizando-se tampão contendo Bis-Tris $50 \mathrm{mM}$ e ácido aminocapróico $500 \mathrm{mM}$ pH 7,0 em géis com gradiente linear de 6 a 13\% de acrilamida, sob um gel de empilhamento de acrilamida a $4 \%$. Foram aplicadas aproximadamente $200 \mathrm{mg}$ de proteína em cada poço do gel.

Para a separação das proteínas foi utilizado tampão do cátodo contendo de Bis-Tris15 mM (pH 7.0), Tricina 50mM (código 22561, USB Corporation) e Coomassie Blue G-250 0.002\% (p/v), e tampão do ânodo contendo Bis- Tris $50 \mathrm{mM}$ (pH 7.0). Utilizamos como padrão de peso molecular o kit de calibração (código 170445-01) fabricado pela GE Healthcare (Buckinghamshire, UK).

Após o final da corrida eletroforética, um dos géis foi fixado em solução de fixação (10\% ácido acético e 40\% de metanol) por 1 hora. A coloração foi realizada durante 2 horas com a solução de coloração contendo 0,1\% Coomassie Brilliant Blue G-250 (código 161-0406, Bio-Rad) e 10\% ácido acético e descorado em solução descorante (10\% Ácido Acético) overnight sob leve agitação. As capturas de imagens foram realizadas pelo ImageScanner PowerLook 1120 (Amersham Biosciences) e analisadas com o auxílio do sofware ImageQuant TL da Amersham Biosciences.

Após a análise do gel em condições nativas, uma tira foi corada e a outra tira sem coloração foi recortada e incubada por 10 minutos com uma solução desnaturante preparada segundo Swamy et al. (2006) contendo Tris 12,5mM (código 75825, USB Corporation), 4\% SDS (código 75819, USB Corporation), 20\% Glicerol (código 16374, USB Corporation) e 0,02\% de Azul de Bromofenol (Bromophenol Blue, código 17-1329-01, GE Healthcare), pH 6,8 acrescida de 9\% $\beta$-Mercaptoetanol (código M6250, Sigma-Aldrich) Após a incubação, as tiras imersas nessa solução foram fervidas. Após o resfriamento, as tiras foram mergulhadas em solução de desnaturação acrescida de $125 \mathrm{mg}$ de Iodoacetamida (código RPN6302, GE Healthcare) por tira e incubada novamente por 15 minutos antes da montagem do gel desnaturante da segunda dimensão.

As eletroforeses em condições desnaturantes foram realizadas com o intuito de separar as diferentes proteínas formadoras do complexo VDAC-ANT-HK que, estaria em uma das bandas detectadas nos géis nativos.

0 gel da segunda dimensão foi realizado como descrito por Schägger et al. (1987), montando-se as placas contendo uma tira do gel nativo, que foi posicionada na parte superior da placa de vidro, tomando-se o cuidado de retirar (com papel filtro), ao máximo possível, a solução contendo $\beta$-mercaptoetanol, que dificulta a polimerização do gel. 0 gel de separação, contendo $10 \%$ de acrilamida, foi colocado na região inferior da placa, com uma pipeta de vidro, sendo recoberto pelo gel de empilhamento com $6 \%$ de acrilamida e, por último, o gel "spacer" a 4\% de acrilamida.

0 tampão utilizado foi o tampão cátodo para gel desnaturante, contendo Tris $0,1 \mathrm{M}$, Tricina $0.1 \mathrm{M}$ e $0,1 \%$ de SDS pH 8,25) e o tampão do ânodo para gel desnaturante, contendo Tris $0,2 \mathrm{M}$ $\mathrm{pH} 8,9$. As corridas eletroforéticas ocorreram a $300 \mathrm{~V}$ e $17,5 \mathrm{~mA}$ por gel. Ao final da corrida os géis utilizados para análises foram corados com uma solução contendo 0,1\% de Coomassie R250 (código B-0149, Sigma), 10\% de ácido acético e 40\% de metanol e descorados com uma solução descorante composta por $10 \%$ de ácido acético e $40 \%$ de metanol. As capturas de imagens foram realizadas pelo ImageScanner PowerLook 1120 (Amersham Biosciences) e analisados no software ImageMaster Platinum versão 6.0 (Amersham Biosciences). 
Western blotting. Após a eletroforese, os géis foram transferidos à $80 \mathrm{~V}, 400 \mathrm{~mA}$ por $1: 40 \mathrm{~h}$ para uma membrana de nitrocelulose com poros de 0,45mm (código RPN303D, GE Healthcare) utilizando a unidade de transferência TE 62 (Amersham Biosciences) e o sistema de tampão de Towbin et al. (1979). As membranas foram bloqueadas pela incubação overnight à $4{ }^{\circ} \mathrm{C}$ em tampão salino contendo Tris $20 \mathrm{mM}$ e NaCl 0,5 M (código S9625, Sigma), pH 7.5 contendo $5 \%$ de leite em pó desnatado (Molico, Nestlé) e 1\% gelatina (código 170-6537, Bio-Rad).

Após o bloqueio, cada membrana foi incubada por 3 horas com anticorpos específicos, diluídos a 1:1000 no tampão acima descrito, para a VDAC 1 (anti-VDAC 131 HL Mouse mAb, código 529532, Calbiochem), 1:200 para a VDAC2 (anti-VDAC2 Rabbit pAb, código ab47104, Abcam), 1:2000 para a HXK (Anti-Hexokinase, código AB 3543, Chemicon International) e 1:200 para a ANT (Anti-ANT, código sc9299, Santa Cruz Biotechnology). Em seguida, as membranas foram incubadas com o anticorpo secundário por 1 hora, diluídos a 1:15000 no tampão contendo gelatina, para Goat Anti-Mouse IgG (código 170-6516, Bio-Rad) para a VDAC 1, 1:10000 e 1:20000 Goat Anti-Rabbit (código 170-6515, Bio-Rad) para a VDAC 2 e HXK, respectivamente e 1:20000 Rabbit Anti-Goat (código 401515, Calbiochem) para a ANT. Em seguida, a quimioluminescência foi detectada usando o sistema SuperSignal West Pico (código 34087, Pierce Chemical) e revelada em filme de raio-X (código 34090, Pierce) no hospital veterinário da Faculdade de Medicina Veterinária e Zootecnia, Universidade de São Paulo - campus de Pirassununga. Entre as etapas, os blottings foram lavados por 3 vezes de 10 minutos com TBS contendo 0,1\% de Tween 20 (código 20605, USB Corporation) e 1 vez de 10 minutos com tampão salino.

\section{RESULTADOS}

0 presente estudo visou determinar a estequiometria do complexo protéico composto pelas VDACs 1 e 2, presente em cérebros de ave, boi e rato. Procuramos identificar se as expressões diferenciadas da VDAC1 e VDAC2 verificadas nos cérebros murino, aviar e bovino, publicadas anteriormente pelo Laboratório (Poleti et al. 2010), estão associadas a diferenças nos interactomas dessas proteínas nesses cérebros.

Na Figura 2 estão esquematizados géis nativos para as amostras mitocondriais aviar, bovina e murina e o padrão de peso molecular utilizado para o cálculo dos pesos dos complexos realizado pelo software. A membrana mitocondrial de neurônio aviar mostrou 12 complexos protéicos, enquanto as amostras bovina e murina evidenciaram 9 complexos protéicos.

As tiras de gel nativo com os complexos protéicos solubilizados foram submetidas a um processo de desnaturação, seguido de uma corrida eletroforética desnaturante, evidenciando, assim, para cada complexo protéico seus diferentes componentes. Aliada à técnica de Western blotting, foi possível identificar as bandas correspondentes às VDACs 1 e 2, ANT e HXK (Fig.3-5). Tais experimentos foram provenientes de 4 amostras biológicas diferentes no caso do cérebro bovino, 12 no caso do cérebro aviar e 15 nos experimentos de cérebro murino.

Na espécie aviar as VDACs 1 e 2 (Fig.6 e 3) estão presentes em cinco complexos protéicos $(643,584,480,445$ e 368 KDa) (Quadro 1). Uma análise mais aprofundada da Fig. 3 permite-nos verificar que ao menos a nível de "immunoblotting", ocorre uma sobreposição da presença das VDACs
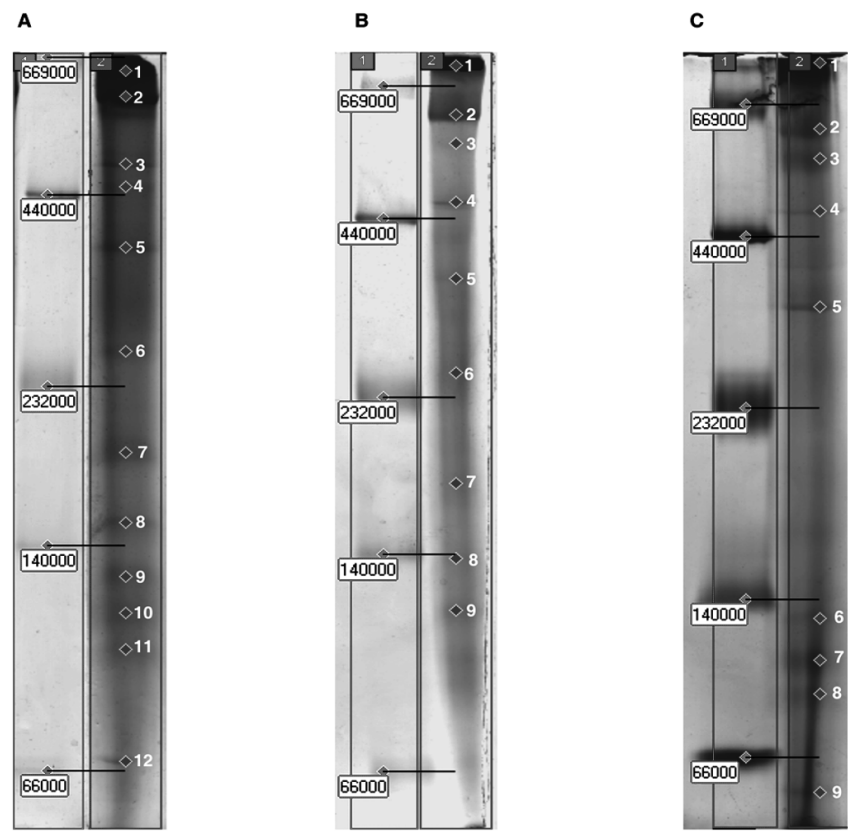

Fig.2. Géis nativos em gradiente de 6-13\% de acrilamida, corados com azul de Comassie . A-amostra aviar; B-amostra bovina e $\mathrm{C}$-amostra murina.

1 e 2 nos mesmos complexos. Por sua vez, o ANT está presente em todos os complexos de membrana mitocondrial nesses neurônios (Fig.3). Finalmente, ao menos a nível de "immunoblotting" a HXK aparece apenas no complexo de baixo peso molecular. Porém, tal observação não nos permite concluir que ela não esteja complexando-se com as VDACs 1 e 2 presentes nos complexos de alto peso molecular, devido provavelmente à baixa expressão dessa proteína no neurônio. Provavelmente, com uma técnica mais acurada como a espectrometria de massa será possível identificar a presença da HXK em complexos de alto peso molecular como de $594 \mathrm{KDa}$ (Fig.3), onde nota-se uma banda de $100 \mathrm{KDa}$ a qual corresponde ao peso da HXK. É importante salientar a interação da HXK e o ANT claramente verificada nesses neurônios. A Figura 6 ilustra os componentes dos complexos protéicos contendo as VDACs 1 e 2 nos neurônios aviares (Quadro 2).

0 "immunoblotting" realizado para a amostra neuronal bovina (Fig.4) identificou as VDACs 1 e 2 em cinco complexos protéicos $(718,597,546,454$ e $404 \mathrm{KDa})$

\section{Quadro 1. Peso molecular dos complexos protéicos da espécie aviar}

Gel Nativo Aviar

Complexos protéicos

Peso Molecular (Da)

1

643.207

2

594.523

3

480.218

4

445.751

5

368.085 


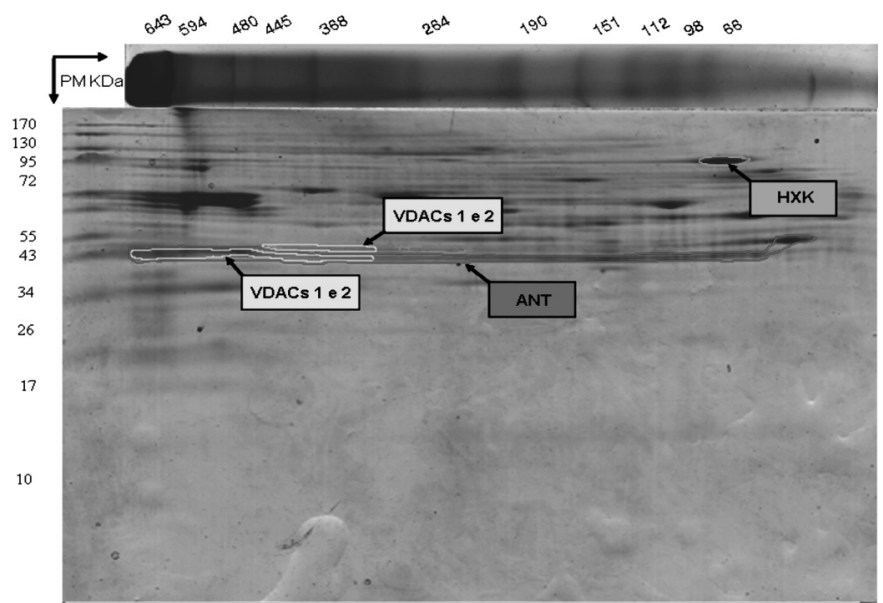

Fig.3. Sobreposição de gel desnaturante e blottings realizados para VDAC1 e 2, HXK e ANT. Tira de gel nativo em gradiente de 6-13\% recortada, incubada e fervida com $9 \%$ $\beta$-mercaptoetanol e incubada com $125 \mathrm{mg}$ de Iodoacetamida/ $5 \mathrm{~mL}$, sobreposta sobre gel de separação desnaturante de Tricina-SDS a $10 \%$ de acrilamida. Amostra neuronal aviar tratada com $1 \%$ DDM.

(Quadro 3). Assim como nos neurônios aviares, ocorreu também a presença de uma sobreposição das VDACs 1 e 2 nos mesmos complexos. Por outro lado, o ANT pelo menos a nível de immunoblotting aparece apenas no complexo de peso molecular $404 \mathrm{KDa}$ em conjunto com as VDACs 1 e 2. Já a hexoquinase aparece apenas nos complexos de baixo peso molecular (124 KDa). Como citado no caso dos neurônios aviares, tais observações não excluem a presença do ANT e da HXK nos complexos de alto peso molecular como o de $716 \mathrm{KDa}$, o que talvez pudesse ser confirmado com a utilização da espectrometria de massas. Tais fatos não minimizam os resultados do presente trabalho, uma vez que temos como foco verificar o número de proteínas interactantes com as VDACs 1 e 2, o que pode ser verificado na Figura 7, a qual ilustra os componentes dos complexos protéicos contendo as

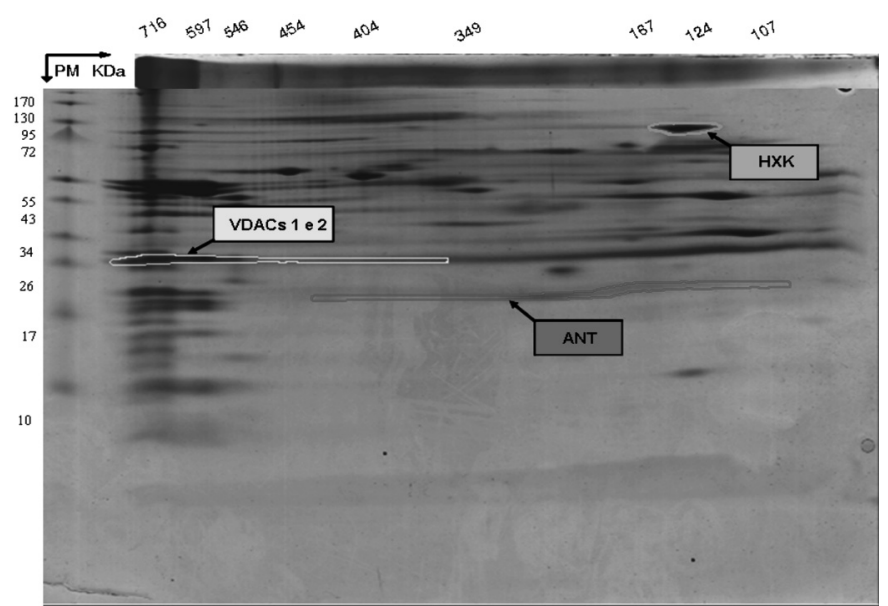

Fig.4. Sobreposição de gel desnaturante e blottings realizados para VDAC1 e 2, HXK e ANT. Tira de gel nativo em gradiente $6-13 \%$ recortada, incubada e fervida com $9 \%$ $\beta$-mercaptoetanol e incubada com $125 \mathrm{mg}$ de Iodoacetamida/ 5mL, sobreposta sobre gel de separação desnaturante de Tricina-SDS a $10 \%$ de acrilamida. Amostra neuronal bovina tratada com $1 \%$ DDM.

VDACs 1 e 2 nos neurônios bovinos (Quadro 4). É importante salientar que é bem clara na Figura 4 a existência da interação do ANT e da HXK.

Na espécie murina as VDACs 1 e 2 foram identificadas somente no complexo protéico de maior massa molecular $(755$ $\mathrm{KDa}$ ) (Fig. 5), não excluindo-se porém possíveis interações com ANT e HXK, uma vez que existem claramente bandas com pesos moleculares dessas proteínas presentes nesse complexo, as quais poderiam ser confirmadas com espectrometria de massas. Uma análise da Figura 5 permite-nos concluir claramente que a ANT e a HXK interagem nesses neurônios. Os componentes do complexo onde estão presentes as VDACs 1 e 2 podem ser visualizados no Quadro 5 (Fig.8).

Levando-se em consideração que em todos os neurônios estudados as VDACs 1 e 2 apareceram no mesmo complexo, e pelo fato de as VDACs serem proteínas alocadas na mem-

Quadro 2. Peso molecular das proteínas constituintes de cada complexo protéico da espécie aviar

\begin{tabular}{|c|c|c|c|c|c|c|c|c|c|}
\hline \multicolumn{2}{|c|}{ Complexo Protéico 1} & \multicolumn{2}{|c|}{ Complexo Protéico 2} & \multicolumn{2}{|c|}{ Complexo Protéico 3} & \multicolumn{2}{|c|}{ Complexo Protéico 4} & \multicolumn{2}{|c|}{ Complexo Protéico 5} \\
\hline Banda & Peso Molecular (Da) & Banda & Peso Molecular (Da) & Banda & Peso Molecular (Da) & Banda & Peso Molecular (Da) & Banda & Peso Molecular (Da) \\
\hline 1 & 78.277 & 1 & 60.145 & 1 & 76.930 & 1 & 76.489 & 1 & 75.618 \\
\hline 2 & 60.145 & 2 & 54.214 & 2 & 61.046 & 2 & 53.018 & 2 & 37.322 \\
\hline 3 & 50.777 & 3 & 49.523 & 3 & 53.253 & 3 & 47.390 & 3 & 35.548 \\
\hline 4 & 42.946 & 4 & 45.285 & 4 & 36.396 & 4 & 44.155 & 4 & 33.856 \\
\hline 5 & 33.405 & 5 & 43.092 & 5 & 34.195 & 5 & 35.794 & 5 & 32.312 \\
\hline 6 & 31.757 & 6 & 36.849 & 6 & 33.595 & 6 & 33.531 & 6 & 28.515 \\
\hline 7 & 30.564 & 7 & 33.343 & 7 & 32.582 & 7 & 30.035 & 7 & 27.326 \\
\hline 8 & 29.630 & 8 & 31.757 & 8 & 30.102 & 8 & 29.514 & 8 & 27.000 \\
\hline 9 & 28.743 & 9 & 30.564 & 9 & 29.543 & 9 & 28.616 & 9 & 26.850 \\
\hline 10 & 28.027 & 10 & 29.601 & 10 & 28.637 & 10 & 26.866 & 10 & 26.637 \\
\hline 11 & 27.668 & 11 & 28.721 & 11 & 26.876 & 11 & 26.653 & Total & 350.983 \\
\hline 12 & 27.443 & 12 & 27.644 & 12 & 26.657 & Total & 432.061 & & \\
\hline 13 & 27.074 & 13 & 27.053 & Total & 469.812 & & & & \\
\hline 14 & 26.932 & 14 & 26.909 & & & & & & \\
\hline 15 & 26.748 & 15 & 26.765 & & & & & & \\
\hline 16 & 26.618 & 16 & 26.689 & & & & & & \\
\hline 17 & 26.453 & Total & 578.154 & & & & & & \\
\hline 18 & 26.417 & & & & & & & & \\
\hline Total & 629.623 & & & & & & & & \\
\hline
\end{tabular}


Quadro 3. Peso molecular dos complexos protéicos da espécie bovina

Gel Nativo Bovino

\begin{tabular}{cc} 
Complexos protéicos & Peso Molecular (Da) \\
\hline 1 & 716.844 \\
2 & 597.083 \\
3 & 546.715 \\
4 & 454.690 \\
5 & 404.288
\end{tabular}

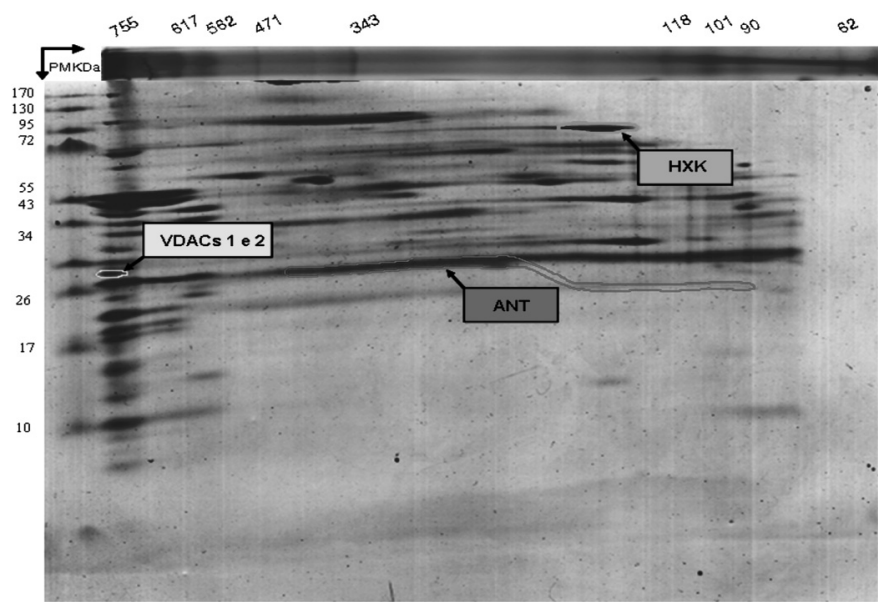

Fig.5. Sobreposição de gel desnaturante e blottings realizados para VDAC1 e 2, HXK e ANT. Tira de gel nativo em gradiente 6-13\% recortada, incubada e fervida com $9 \% \beta$-mercaptoetanol e incubada com $125 \mathrm{mg}$ de Iodoacetamida/ $5 \mathrm{~mL}$, sobreposta sobre gel de separação desnaturante de Tricina-SDS a 10\% de acrilamida. Amostra neuronal murina tratada com 1\% DDM.

brana mitocondrial interna, às quais ancoram-se várias outras proteínas, resolvemos utilizá-las como proteínas alvo dos complexos interactômicos. Dessa maneira, verificamos que na mitocôndria neuronal aviar, as VDACs 1 e 2 do complexo 1 interagem com 18 proteínas e nos complexos 2, 3, 4 e 5 com 16, 12, 11 e 10 proteínas, respectivamente (Quadro 2). Os valores dos pesos moleculares das proteínas interactantes com as VDACs aviares podem ser visualizados nos Quadro 2.
Por sua vez, na mitocôndria neuronal bovina, as VDACs 1 e 2 do complexo 1 interagem com 15 proteínas e nos complexos 2, 3, 4 e 5 com 13, 10, 08 e 07 proteínas, respectiva-

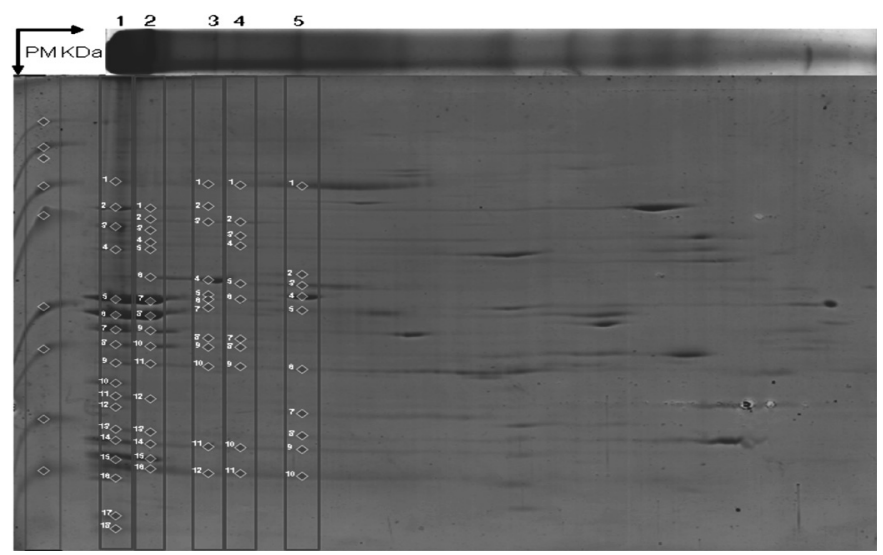

Fig.6. Sobreposição de gel não desnaturante (primeira dimensão) e gel desnaturante de SDS-PAGE (segunda dimensão). Mitocôndria neuronal aviar, as VDACs 1 e 2 do complexo 1 interagem com 18 proteínas e nos complexos 2, 3, 4 e 5 com 15, 11, 10 e 09 proteínas, respectivamente.

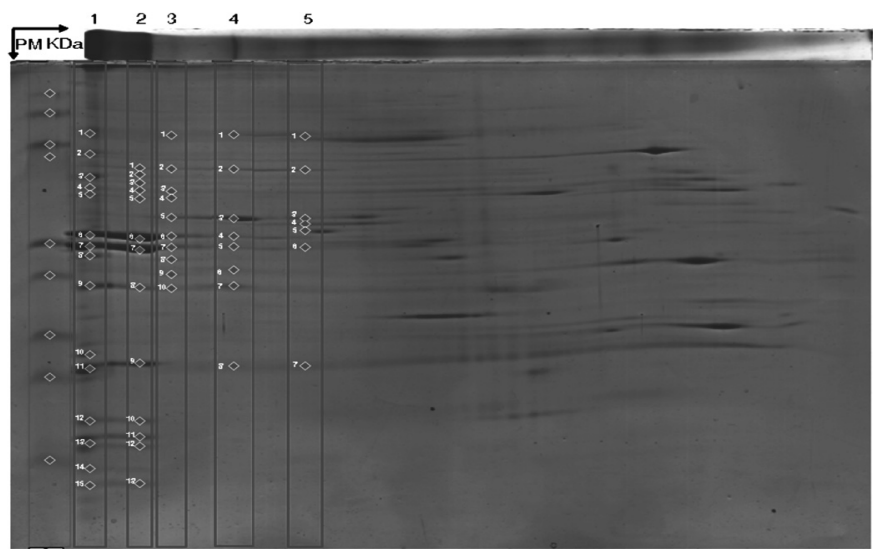

Fig.7. Sobreposição de gel não desnaturante (primeira dimensão) e gel desnaturante de SDS-PAGE (segunda dimensão). Na mitocôndria neuronal bovina, as VDACs 1 e 2 do complexo 1 interagem com 14 proteínas e nos complexos 2, 3, 4 e 5 com 12, 09, 07 e 06 proteínas, respectivamente.

Quadro 4. Peso molecular das proteínas constituintes de cada complexo protéico da espécie bovina

\begin{tabular}{|c|c|c|c|c|c|c|c|c|c|}
\hline \multicolumn{2}{|c|}{ Complexo Protéico 1} & \multicolumn{2}{|c|}{ Complexo Protéico 2} & \multicolumn{2}{|c|}{ Complexo Protéico 3} & \multicolumn{2}{|c|}{ Complexo Protéico 4} & \multicolumn{2}{|c|}{ Complexo Protéico 5} \\
\hline Banda & Peso Molecular (Da) & Banda & Peso Molecular (Da) & Banda & Peso Molecular (Da) & Banda & Peso Molecular (Da) & Banda & Peso Molecular (Da) \\
\hline 1 & 105.648 & 1 & 75.031 & 1 & 103.767 & 1 & 103.767 & 1 & 102.538 \\
\hline 2 & 85.331 & 2 & 70.226 & 2 & 74.259 & 2 & 73.499 & 2 & 73.499 \\
\hline 3 & 68.846 & 3 & 65.270 & 3 & 61.151 & 3 & 49.700 & 3 & 50.075 \\
\hline 4 & 62.860 & 4 & 61.712 & 4 & 57.971 & 4 & 44.443 & 4 & 48.083 \\
\hline 5 & 59.523 & 5 & 57.720 & 5 & 50.265 & 5 & 41.904 & 5 & 46.100 \\
\hline 6 & 44.881 & 6 & 43.876 & 6 & 44.588 & 6 & 37.580 & 6 & 41.904 \\
\hline 7 & 42.153 & 7 & 41.297 & 7 & 42.028 & 7 & 35.274 & 7 & 29.309 \\
\hline 8 & 40.155 & 8 & 35.204 & 8 & 39.512 & 8 & 29.263 & Total & 391.507 \\
\hline 9 & 35.416 & 9 & 29.401 & 9 & 36.973 & Total & 415.430 & & \\
\hline 10 & 29.803 & 10 & 27.760 & 10 & 35.065 & & & & \\
\hline 11 & 29.197 & 11 & 27.490 & Total & 545.580 & & & & \\
\hline 12 & 27.760 & 12 & 27.359 & & & & & & \\
\hline 13 & 27.404 & 13 & 26.986 & & & & & & \\
\hline 14 & 27.113 & Total & 589.333 & & & & & & \\
\hline 15 & 26.978 & & & & & & & & \\
\hline Total & 713.067 & & & & & & & & \\
\hline
\end{tabular}




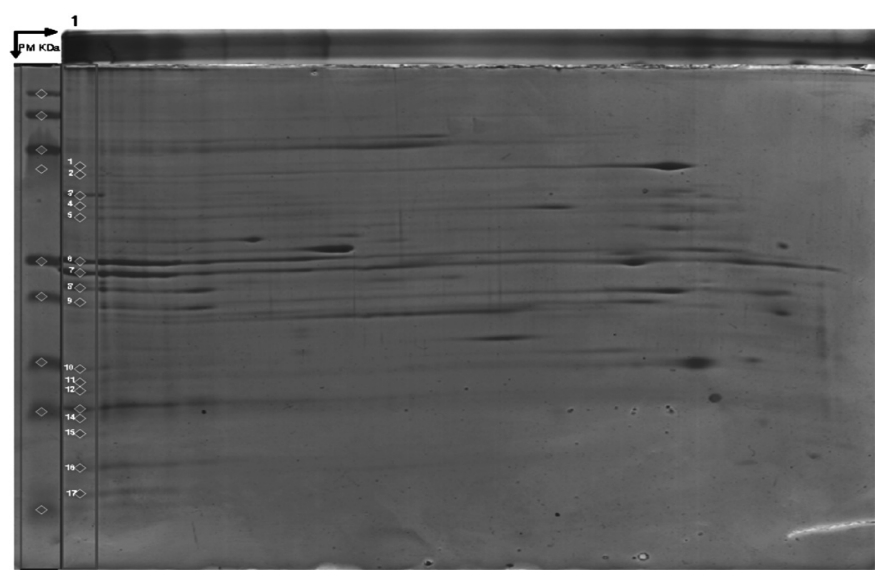

Fig.8. Sobreposição de gel não desnaturante (primeira dimensão) e gel desnaturante de SDS-PAGE (segunda dimensão). A mitocôndria neuronal murina as VDACs 1 e 2 do complexo 1 interagem com 16 proteínas.

mente (Quadro 4). Os valores dos pesos moleculares das proteínas interactantes com as VDACs bovinas podem ser visualizados no Quadro 4.

Já na mitocôndria neuronal murina as VDACs 1 e 2 do complexo 1 interagem com 17 proteínas (Quadro 6). Os valores dos pesos moleculares das proteínas interactantes com as VDACs murinas podem ser visualizados no Quadro 6. É notável a diferença de interação das VDAC 1 e 2 na espécie murina em relação aos neurônios das demais espécies. Nessas células as VDACs 1 e 2 aparecem em apenas um grande complexo protéico, ao contrário das outras células estudadas, nas quais essas proteínas aparecem em cinco diferentes associações.

Quadro 5. Peso molecular dos complexos protéicos da espécie murina

\begin{tabular}{cc}
\hline \multicolumn{2}{c}{ Gel Nativo Murino } \\
\hline Complexos protéico & Peso Molecular (Da) \\
\hline 1 & 755.918
\end{tabular}

Quadro 6. Peso molecular das proteínas constituintes de cada complexo protéico de murino

\begin{tabular}{cc}
\hline \multicolumn{2}{c}{ Complexos protéico } \\
\hline Banda & Peso Molecular (Da) \\
\hline 1 & 83.948 \\
2 & 79.076 \\
3 & 67.297 \\
4 & 62.281 \\
5 & 57.422 \\
6 & 44.282 \\
7 & 41.870 \\
8 & 39.082 \\
9 & 36.909 \\
10 & 30.323 \\
11 & 29.516 \\
12 & 29.045 \\
13 & 28.262 \\
14 & 27.937 \\
15 & 27.377 \\
16 & 26.540 \\
17 & 26.081 \\
Total & 737.248
\end{tabular}

\section{DISCUSSÃO}

A VDAC, também conhecida como porina, é a proteína mais abundante presente da membrana mitocondrial externa (Desagher \& Martinou 2000). Estudo anterior do laboratório, mostrou que a expressão diferenciada das isoformas da VDAC nas espécies aviar, bovina e murina estão relacionadas às diferenças no metabolismo energético neuronal de cada espécie (Poleti et al. 2010).

Paralelamente, Crawford (1970) reportou que aves epiléticas exibiram crises tônico-clônicas generalizadas em resposta à fotoestimulação intermitente (FEI) e acústica. A partir deste estudo, a caracterização bioquímica e fisiológica das aves epiléticas continua a fornecer uma visão dos mecanismos básicos de epilepsia. Trata-se de um modelo bem adequado para explorar a relação entre tremores periódicos generalizados e patologia neuronal (Gong et al. 2003). Além disso, as aves epiléticas correspondem similarmente, por uma perspectiva farmacológica, ao ser humano epilético. Os medicamentos anticonvulsivantes comuns, usados em pessoas que apresentam epilepsia do tipo grande-mal, foram igualmente eficazes na prevenção de tremores induzidos por fotostimulação intermitente (FEI) em aves epiléticas. As benzodiazepinas amplamente utilizadas em síndromes epiléticas são um poderoso anticonvulsivante em aves epiléticas. Portanto, de uma perspectiva comportamental, farmacológica, bioquímica, histológica e anatômica, as aves são um razoável modelo biológico para epilepsia do tipo grande-mal em humanos (Kendall et al. 2002).

Estudo anterior do Laboratório identificou diferenças significativas entre o nível de expressão da VDAC 1 e da VDAC 2 nas espécies bovina, murina e aviar (Poleti et al. 2010). A VDAC 1 foi a isoforma mais expressa em todas as espécies, porém apenas no cérebro aviar, a VDAC 1 apresentou uma expressão significativamente maior em relação à VDAC 2, quadro semelhante ao observado na epilepsia fármaco-resistente (Jiang et al. 2007). A espécie murina apresentou a menor expressão da VDAC 1 em relação às outras espécies. Já a VDAC 2 apresentou os níveis mais altos de expressão em mitocôndrias de cérebro bovino em relação à ave, que apresenta os menores níveis de VDAC 2 . Nas mitocôndrias do cérebro de murino os valores de VDAC 2 foram intermediários. A isoforma VDAC 3 não foi encontrada neste estudo (Poleti et al. 2010).

No presente trabalho, a mitocôndria neuronal aviar apresentou o maior número de complexos protéicos (12) quando comparada às espécies bovina e murina, as quais apresentaram 9 complexos protéicos.

A cinética de complexação da VDAC nas diferentes mitocôndrias evidenciou diferenças marcantes. No cérebro murino, esta proteína esteve presente em apenas um complexo, enquanto nos outros cérebros a mesma apresentou cinco interactomas distintos. Tal situação evidencia possíveis interações funcionais diferenciais nesses diferentes sistemas.

No complexo protéico de maior peso molecular da espécie aviar (643 KDa) as isoformas de VDAC 1 e 2 apresentaram-se complexadas com maior número de proteínas (18) quando comparadas com as interações nas outras espécies. Tal fato evidência um interactoma diferenciado da VDAC 
neuronal no cérebro aviar. Esta observação poderia estar relacionada com os diferentes mecanismos energéticos e apoptóticos evidenciados neste cérebro.

Agradecimentos.- Esse projeto teve suporte da Fundação de Amparo à Pesquisa do Estado de São Paulo (Proc.2010/05560-6). Carla Rossini Crepaldi foi bolsista nível mestrado da Fundação de Amparo à Pesquisa do Estado de São Paulo (Proc.2009/06687-2).

\section{REFERÊNCIAS}

Abu-Hamad S., Sivan S. \& Shoshan-Barmatz V. 2006. The expression level of the voltage-dependent anion channel controls life and death of the cell. Proc. Natl Acad. Sci. USA 103:5787-5792.

Cerqueira Cesar M. \& Wilson J.E. 2002. Functional characteristics of hexokinase bound to the Type A and Type B sites of bovine brain mitochondria. Archs Biochem. Biophys. 397:106-112.

Cerqueira Cesar M. \& Wilson J.E. 2004. All three isoforms of the voltage-dependent anion channel (VDAC1, VDAC2, and VDAC3) are present in mitochondria from bovine, rabbit, and rat brain. Archs Biochem. Biophys. 422:191-196.

Crawford R.D. 1970. Epileptiform seizures in domestic fowl. J. Hered. 61:185-188

Cheng E., Sheiko T., Fischer J., Craigen W. \& Korsmeyer S. 2003. VDAC2 inhibits bak activation and mitochondrial apoptosis. Science 301:513517.

Desagher S. \& Martinou J. 2000. Mitochondria as the central control point of apoptosis. Trends Cell Biol. 10:369-377.

Gong Z., Obenaus A., Li N., Sarty G. \& Kendall E. 2003. recurrent nonstatus generalized seizures alter the developing chicken brain. Epilepsia 44:1380-1387.

Hastings T.G. 2009. The role of dopamine oxidation in mitochondrial dysfunction: implications for Parkinson's disease. J. Bioenerg. Biomembr. 41:469-472.

Jiang W., Du B., Chi Z., Ma L., Wang S., Zhang X., Wu W., Wang X., Xu G. \& Guo C. 2007. Preliminary explorations of the role of mitochondrial proteins in refractory epilepsy: some findings from comparative proteomics. J. Neurosci. Res. 85:3160-3170.

Kendall E., Gong Z., Tuchek J. \& Obenaus A. 2002. Physical and chemical characterization of neurological injury in an avian model of primary generalized epilepsy. Image Anal. Stereol. 21:77-86.
Kroemer G., Galluzzi L. \& Brenner C. 2007. mitochondrial membrane permeabilization in cell death. Physiol. Rev. 87:99-163.

Lai J.C.K. \& Clark J.B. 1979. Preparation of synaptic and nonsynaptic mitochondria from mammalian brain. Methods Enzymol. 55:51-60.

Poleti M., Tesch A., Crepaldi C., Souza G., Eberlin M. \& Cerqueira César M. 2010. Relationship Between expression of voltage-dependent anion channel (vdac) isoforms and type of hexokinase binding sites on brain mitochondria. J. Mol. Neurosci. 41:48-54

Rahmani Z., Maunoury C. \& Siddiqui A. 1998. Isolation of a novel human voltage-dependent anion channel gene. Eur. J. Hum. Genet. 6:337-340.

Reisinger V. \& Eichacker L. 2007. How to analyse protein complexes by 2D Blue Native SDS-PAGE. Practical Proteomics 1:6-16.

Rodriguez-Enriquez S., He L. \& Lemasters J. 2004. Role of mitochondrial permeability transition pores in mitochondrial autophagy. Int. J. Biochem. Cell Biol. 36:2463-2472.

Schägger H. \& Jagow G. 1987. Tricine-sodium dodecyl sulfate-polyacrylamide gel electrophoresis for the separation of proteins in the range from 1 to $100 \mathrm{kda}$. Anal. Biochem. 166:368-379.

Schägger H., Cramer W. \& Jagow G. 1994. Analyses of molecular mass and oligomeric states of protein complexes by Blue Native Electrophoresis and isolation of membrane protein complexes by two-dimensional native electrophoresis. Anal. Biochem. 217:220-230.

Scorza F.A., Albuquerque R., Arida R.M., Schmidt B., Almeida A.G., Scorza C.A. \& Cavalheiro E.A. 2009. Could sudden death syndrome (SDS) in chickens (Gallus gallus) be a valid animal model for sudden unexpected death in epilepsy (SUDEP)? Med. Hypotheses 73:67-69.

Swamy M., Siegers G., Minguet S., Wollscheid B. \& Schamel W. 2006. Blue Native Polyacrylamide Gel Electrophoresis (BN-PAGE) for the identification and analysis of multiprotein complexes. Sci STKE 345:1-17.

Törnroth-Horsefield S. \& Neutze R. 2008. Opening and closing the metabolite gate. Proc. Natl Acad. Sci. USA 105:19565-19566.

Wittig I., Beckhaus T., Wumaier Z., Karas M. \& Schägger H. 2010. Mass estimation of native proteins by Blue-Native Electrophoresis: principles and practical hints. Mol. Cell Proteomics 9:2149-2161.

Yoo B., Fountoulakis M., Cairns N. \& Lubec G. 2001. Changes of voltage-dependent anion selective channel proteins VDAC 1 and VDAC 2 brain levels in patients with Alzheimer's disease and Down Syndrome. Electrophoresis 22:172-179. 